\title{
Psychological contract breach as a stressor in the physician's job commitment-extra-role behaviour relationship
}

\section{Samuel Koomson}

Published online: 25 December 2021.

\begin{abstract}
This paper finds out if a committed physician will go the extra mile for his/her employer when faced with psychological contract breach (PCB), a psychosocial stressor. Data from 214 physicians across 26 health-care units in the Upper East (UE) and Upper West (UW) regions of Ghana were analysed. A semi-structured, pre-tested and validated questionnaire was utilised. Research philosophy was positivism, research approach was quantitative, research design was explanatory, and study design was cross-sectional. Preliminary tests were conducted. Both reflective measurement and structural models were examined. PLS algorithm tool and bootstrapping procedure were used. Control variables were sex, age, employment type and tenure. A significant level was set at 5\%. Smart PLS and IBM SPSS software were employed. In the end, physician's commitment work (JCM) positively and significantly predicted extra-role behaviour (ETB). Also, PCB significantly interacted with JCM to predict ETB, such that the relationship between JCT and ETB was stronger when PCB was low than when it was high. Creating a balanced, fulfilled and harmonious hospital-physician relationship will transform the workplace into a less stressful, more meaningful and purposeful atmosphere for the benefit other health-care professionals, patients and the health-care organisation at large.
\end{abstract}

Keywords: attitudes; discretionary behaviour; hospital-physician exchanges; moderation; partial least square-structural equation modeling; unfulfilled expectations

\section{INTRODUCTION}

\section{Background}

In the health-care setting, the conception of a psychological contract (PC) indicates that a set of anticipations always exist between every health-care worker of a health-care unit and the several executives and others in that unit (Huy \& Takahashi, 2018). Health-care units, on one hand, may expect health-care professionals to do their best on behalf of the health-care unit: to make themselves available for the heath-care facility; to be fully committed to its values, to be compliant and loyal; and to improve the image of the facility with its patients and suppliers (Rousseau \& Greller, 1994). Health-care professionals, on the other hand, may expect to be treated impartially as humans, to be offered assignments that uses their abilities, to be paid fairly in line with their efforts, to be able to show competence, to have opportunities for future

Department of Management University of Cape Coast (UCC) Ghana

\section{*) corresponding author}

Samuel Koomson

Email:skoomson68@gmail.com development, to know what is expected of them, to be given feedback-preferably positive-on their performance, to be part of decision-making, and to have faith in the executives of the health-care facility to keep their promises (Guest et al., 1996). This statement underscores the $8^{\text {th }}$ and $16^{\text {th }} \mathrm{UN}$ Sustainable Development Goal, which seeks to offer decent work and economic development for everyone, and enhance peaceable and inclusive community for sustainable development respectively (Catholic Agency for Overseas Development, 2015).

Gallup's State of the American Workplace Report (2017) advocates that health-care professionals must be in a setting where there is mutual trust, recognition and respect for one another's efforts and results. Ghana Healthcare Quality Strategy Report (2017) also declares the relevance for health-care executives to construct a philosophy of "joy at work" in terms of financing, logistics, recognition and rewards to give room for health-care workers to solemnly work as a team, and deliver high quality care, and be motivated to continuously improve quality. The assertion put forward by the Ghana Healthcare Quality Strategy Report (2017) matches up with the core mission of the Ghana Health Service (2017), which pursues to establish a more equitable, efficient, accessible and responsive healthcare system.

A PC is said to have been honoured when the healthcare facility meets its obligations to an health-care professional, from the professional's vantage, and it serves to build upon the social exchange element (Karagonlar et al., 
2016), which are founded on trust, reciprocation and reward (Blau, 1964). In contrast, a PC is said to have been breached if the health-care facility fails to deliver on an expected obligation to the professional and this expected obligation can either be documented or undocumented (Robinson \& Rousseau, 1994). When a PC is honoured, health-care professionals are likely to be highly committed to their jobs. On the contrary, when a PC is in breach or unfulfilled, there is the tendency for health-care professionals to show low levels of JCM (Agbozo et al., 2018). Job commitment is a strong desire to remain a member of a particular organisation, the desire to strive at what organisation desires and certain beliefs and acceptance of value and purpose of the organisation (Akbar et al., 2018).

The negative relationship between PCB and JCM is described by the social exchange theory (SET), which one of the most applied conceptual paradigms for understanding workplace behaviour (Cropanzano et al., 2017; Opoku Mensah \& Koomson, 2021). According to the SET, when the organisation helps the employee out, the employee is likely to do something in return for the organisation. But, if the employee senses that the organisation does not have his/her best interest at heart, the employee is likely to show undesirable work attitudes (Organ, 2018), such low level of JCM.

An employee who is less committed is not likely to go an extra mile for his/her organisation. A committed employee, on the other hand, presents benefits to coworkers, customers, and the organisation at large. As an evidence, Leephaijaroen (2016) shows that continuance commitment and affective commitment positively and significantly affected citizenship behaviour among university support workers in Thailand. Anggraeni et al. (2017) also report that JCM positively and significantly influenced citizenship behaviour among Indonesian young entrepreneurs. Thus, it is understood that ground-breaking transformations in organisations are a result of committed employees. The positive relationship JCM and ETB is described the resource-based theory (RBT). The RBT regards a committed employee as a firm resource or asset which is able to generate value or competitive advantage by being rare and difficult to imitate by rival firms (Rezaei \& Ortt, 2018). This competitive advantage converts into positive organisational outcomes, in the form of discretionary behaviour for the benefit of co-workers, customers and the organisation itself. Thus, the SET and RBT aids in understanding the relationship between PCB and JCM, and JCM and ETB respectively.

The SET, as power as it is, offers additional understanding on the negative relationship between PCB and ETB, such that when an employee feels breached psychological, he/she is unlikely to demonstrate discretionary behaviour for the benefit of the employer/organisation. Organ (2018) educates that ETB is a free, voluntary and selfless interest for the good of others, such as organisation, clients/customers, clients' relatives or groups. In the healthcare sector in particular, Gupta (2019) explains that ETB exhibited by health-care professionals has the potential of boosting the satisfaction of co-workers, patients, patients' friends, and their relatives. As proof, Shen et al. (2019) report a negative linkage between PCB and ETB among employees and supervisors in China. Koomson and Opoku Mensah (2020) also share that PCB caused medical doctors to show low citizenship behaviour in Ghana.

Beside the SET and the RBT, this study utilises the activation theory (ACT) to describe the proposed moderating role of $P C B$ in the direct relationship between JCM and ETB, such that the direct positive relationship between JCM and ETB may be weakened by a high-PCB, but strengthened by a fulfilled PC or low-PCB. The ACT (Gardner, 1986; Gardner \& Cummings, 1988) holds that too much stress from the employer can damaged an employee's ability to perform, particularly for complex and difficult task (Gardner, 1990), thereby negating the tendency of that employee to show discretionary behaviour. This assumption has been tested by related authors in different models. For example, Addae et al. (2006) reveal that employees with high affective commitment who perceived a PCB were more likely to think about quitting their jobs. Paille et al. (2014) find that PCB moderated the direct linkage between perceived organisational support and job satisfaction. Paillé and Rainer (2015) disclose that PCB moderated the linkage between perceived organisational support and eco-initiatives. Haque et al. (2016) educate that PCB moderated the direct positive relationship between psychological capital and work engagement, and the direct negative relationship between psychological capital and burnout.

Gupta et al. (2016) argues that PCB moderated the connection between perceived organisational support and work engagement, as well as the nexus between perceived organisational support and ETB. Erkutlu and Chafra (2016) uncover that high-PCB weakened the positive relationship between benevolent leadership and psychological wellbeing. Santhanam et al. (2017) discover that PCB moderated the nexus between human resource management practices and turnover. Against this background, this study seeks to examine the direct relationship between JCT and ETB among physicians in Ghana, and further test the moderating role of $\mathrm{PCB}$, a psychosocial stressor, on this direct relationship.

\section{Problem statement}

Statistics retrieved from Ghana Health Service seem to suggest that severe $\mathrm{PCB}$ among physicians working in the Upper East (UE) and Upper West (UW) Regions of Ghana, where regional inequalities exist in terms of the distribution of physicians, hospital admission rates, number of available hospital beds, available health facilities, and doctorpopulation ratio (Ghana Health Service, 2018). In particular, the hospital admission rates for UE and UW Regions have been relatively high for three years consistently, from 2015 to 2017. Concomitantly, the number of hospital beds available to serve Ghanaians living in these two regions has been relatively low from 2016 to 2017 . Besides, the total number of health facilities, such as chip compounds, clinics, and hospitals in these two regions has been comparably minimal from 2016 to 2017. To make matters worse, the doctor-population ratio for the two regions have been relatively high from 2011 to 2017, with UE Region topping the table by recording one doctor to 26,489 population for the year 2017.

This unfavourable condition is not the same for their colleagues in the other regions of Ghana (Ghana Health Service, 2018). Meanwhile, little recognition is given to them for their efforts, as they are placed on the same salary arrangement with their colleagues in the other regions (Larbi, 2015). These unfair instances put severe pressure or stress on the physicians working in these two regions. This stress can be likened to high-PCB on the part of their healthcare employer, which may eventually lead the physicians to show low levels of JCM (Hazrati, 2017), as well as low ETB (Koomson \& Opoku Mensah, 2020), as explained by the SET. Besides, this high-PCB could demoralise a committed physician and supress his/her effort to offer ETB, with its associated benefits. Stated differently, this high-PCB may suppress the direct positive linkage between JCM and ETB, as explicated by the ACT. As a consequence, this study 
examines the moderating role of $\mathrm{PCB}$ on the direct relationship between JCM and ETB among physicians working in the UE and UW Regions of Ghana.

\section{Research gab}

There is a dearth of literature on the moderating effect of PCB on the direct relationship between JCM and ETB, limiting the applicability of the SET, RBT and ACT. Existing studies have modelled $\mathrm{PCB}$ as a moderator in different direct path, such as human resource management practices and employee turnover intentions (Santhanam et al., 2017), perceived organisational support and work engagement (Gupta et al., 2016), perceived organisational support and ETB (Gupta et al., 2016), benevolent leadership and psychological well-being (Erkutlu \& Chafra, 2016), perceived corporate environmental policies and employees eco-initiatives (Paillé \& Raineri, 2015), and organisational commitment and intentions to quit (Addae et al., 2006). In addition, these studies were conducted in western countries, ignoring Sub-Saharan Africa, particularly Ghana. Also, few related studies have applied PLS-SEM, which is argued to be superior analytical tool in drawing conclusions. Besides, these studies overlooked the views of physicians who work in the health-care settings. To address these gaps in the literature, this study offers health-care literature on the moderating role of $\mathrm{PCB}$ on the direct relationship between JCM and ETB among physicians working in the UE and UW Regions of Ghana.

\section{Literature Review and Hypotheses Development}

\section{Resource-based theory (RBT)}

The RBT regard a committed employee as a firm resource or asset which is able to generate value or competitive advantage by being rare and difficult to imitate by rival firms (Rezaei \& Ortt, 2018). This competitive advantage converts to positive organisational outcomes. To illustrate, Leephaijaroen (2016) shows that continuance commitment and affective commitment positively and significantly affected citizenship behaviour among university support workers in Thailand. Anggraeni et al. (2017) also report that JCM positively and significantly influenced citizenship behaviour among Indonesian young entrepreneurs. In line with the result of earlier related studies and assumptions of the SET, the first hypothesis of this study is formulated as follows:

$\mathrm{H}_{1}=\mathrm{JCM}$ has a positive and significant relationship with ETB

\section{Social exchange theory (SET)}

The SET (Blau, 1964) is one of the most applied conceptual paradigms for understanding workplace behaviour. The SET advocates that favours are done with the intention that later return will occur (Cropanzano et al., 2017). The theory proposes that, if the organisation helps the employee out, the employee is more likely to do something in return for the organisation (Golden \& Veiga, 2018). Fallon and Rice (2015) argue that employees will behave favourably within firms when they perceive that the organisation as having their best interests at heart, by offering them safe working environment, working tools, equipment, focused training, career development plans, new learning opportunities, and many more.

When employees' PC with their employer is honoured, they become happy (Roy \& Konwar, 2019) and they are likely show positive workplace behaviour. Nonetheless, when their PC is in breach, they reciprocate by show undesirable behaviour. For instance, Hazrati (2017) revealed that $\mathrm{PCB}$ negatively predicted affective commitment among banking sector employees in Dubai. Opoku Mensah and Koomson (2021) utilised the SET and showed that an unfulfilled PC led to low ETB among healthcare professionals in Ghana. Therefore, the SET provides understanding on the negative effect of PCB on JCM, as well as the negative connection between $\mathrm{PCB}$ and $\mathrm{ETB}$, which aids in understanding the moderating effect of $P C B$ on the direct relationship between JCT and ETB.

\section{Activation Theory (ACT)}

The ACT (Gardner, 1986; Gardner \& Cummings, 1988) assumes that too much stress caused by the employer can damaged an employee's ability to perform, particularly for complex and difficult task (Gardner, 1990), thereby negating the tendency of that employee to show extra-role behaviour. According to the ACT, at this moderate level, employees would make full use of cognitive resources, which will bring positive impacts (Baer \& Oldham, 2006) for the benefit of co-workers, customers and the organisational at large. Nevertheless, too much of stress limits the employees' ability to perform a task or show discretionary behaviour. Thus, this study utilises the ACT in explaining the proposed moderating role of $\mathrm{PCB}$, a psychosocial stressor, in the direct relationship between JCM and ETB, such that the direct positive relationship between JCT and ETB is weakened by a high-PCB, but strengthened by low-PCB or a fulfilled PC.

This idea addressed by the ACT is backed by other studies who have modelled PCB as a moderator in a few direct relationships. For instance, Addae et al. (2006) revealed that media employees in Trinidad and Tobago with high affective commitment who perceived a PCB were more likely to think about quitting their jobs. Paille et al. (2014) found that PCB moderated the direct linkage between perceived organisational support and job satisfaction. Paillé and Rainer (2015) unveiled that PCB moderated the linkage between perceived organisational support and ecoinitiatives among alumni of MBA programmes in a Canadian University. Haque et al. (2016) reported that PCB moderated the direct positive relationship between psychological capital and work engagement, as well as the direct negative relationship between psychological capital and burnout among doctors working in direct health-care units in Pakistan.

Gupta et al. (2016) showed that PCB moderated the connection between perceived organisational support and work engagement, as well as the nexus between perceived organisational support and ETB among nurses in India. Erkutlu and Chafra (2016) uncovered that high-PCB weakened the positive relationship between benevolent leadership and psychological well-being among five-star hotel employees in Turkey. Santhanam et al. (2017) disclosed that PCB moderated the nexus between human resource management practices and turnover intentions among frontline employees in Indian hospitality industry. With this in mind, the second hypothesis is formulated as follows:

$\mathrm{H}_{2}=\mathrm{PCB}$ will moderate the positive effect of JCM on ETB, such that a committed physician who senses high-PCB will be less likely to demonstrate ETB than one who perceives low-PCB 


\section{Conceptual framework}

Underpinned in the SET, RBT and ACT, a conceptual framework is designed in Figure 1 to describe the direct effect of JCM on ETB (hypothesis 1), and the moderating effect of PCB on this direct path (hypothesis 2). JCM serves as the exogenous latent variable, while ETB is used as the endogenous latent variable. $\mathrm{PCB}$ is utilised as a moderator in this study. Sex (CTL1), age (CTL2), employment type (CTL3) and tenure (CTL4) are used as control variables, with lessons from existing related studies.

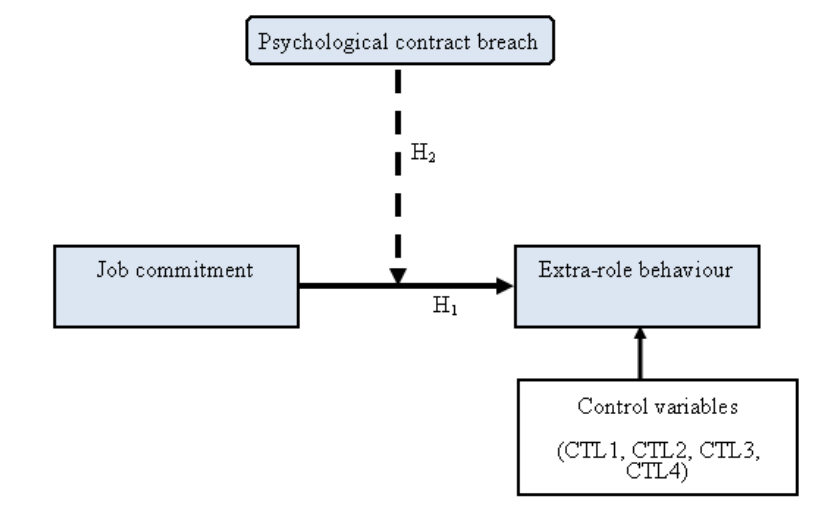

Figure 1. Conceptual framework

\section{MATERIALS AND METHODS}

The study employed the positivist philosophical paradigm, which believes in an objective reality. Research approach was quantitative and research design was explanatory. The cross-sectional study design was used. The target population consisted of all physicians working in the UE ( $n=99)$ and UW ( $n=152)$ Regions, making at total of 251 physicians. A census was employed. A semi-structured questionnaire was used for data collection. The questionnaire was designed to cater for common method variance using the recommendations made by Podsakoff et al. (2003), such as the use of multiple scale formats and reverse-coded items. The questionnaire was made up of 54 items. Section 'A' considered 15 items that measured PCB sourced from the study by Conway and Briner (2005), and measured on a 7-point Likert-type interval scale ranging from 1: least agreement to 7=strongest agreement. Sample item was: 'Limited materials and equipment are made available to me to perform my job' (PCB01).

Section 'B' covered JCM. Meyer and Allan's (1997) 19item scale was used to measure JCM. The 19-items were anchored on a seven-point Likert-type interval scale with score 1 =least agreement to $7=$ strongest agreement. Sample item was: 'I have the chance to do something that makes use of my abilities' (JCM11). Section ' $C$ ' of the instrument considered ETB. The 16-item organisational citizenship behaviour scale by Lee and Allen (2002) was utilised. This scale was anchored on a seven-point Likert-type interval scale with score $1=$ never to $7=$ every time. The scale was used because of its balance between length and psychometric properties. Sample item was: 'Willingly give my time to help others who have work-related problems' (ETB-I-2). Finally, 'Section D' of the questionnaire looked at the background information of respondents. The information sought were sex ( $1=$ male; $0=$ female), age (in years), employment type ( 1 = fulltime employment; $0=$ part time), and the number of years worked (in years), as used in earlier studies (Koomson \& Opoku Mensah, 2020; Opoku Mensah \& Koomson, 2021).

Of the 251 physicians targeted, 218 responded to the instrument. Of the 218 questionnaires retrieved, 4 were extremely incomplete (missing values $>5 \%$ ), hence they were rejected. The remaining 214 completed questionnaires were used for data processing and analysis. In the end, a response rate of $85 \%$ was attained. The data collected were subjected to Kolmogorow-Smirnov Test, Kaiser-MeyerOlkin (KMO) measure of sampling adequacy test and Bartlett Test of Sphericity. Then, reliability and validity tests were run using the guidelines recommended by Hair et al. (2014), namely indicator reliability, internal consistency reliability, convergent validity and discriminant validity. Moderation test was conducted using the product indicator approach. Control variables were sex (CTL1), age (CTL2), employment type (CTL3) and tenure (CTL4). A significant level was set at 5\%. Smart PLS 2.0M.3 by Ringle et al. (2005) and IBM SPSS Statistics Software for windows, version 24 were applied. The PLS algorithm was run, using the default setting with Initial Weights set at 1.00, Maximum Iterations of 300 and an abort criterion of 1.0E-5. The bootstrap of the 214 cases was run, using 5000 bootstrap samples, with no sign changes. The product indicator approach was used for the moderation analysis.

\section{RESULT}

\section{Background information of respondents}

Table 1 shows the background information of respondents, regarding their sex, age, employment type, and number of years worked with employer.

\section{Test of normality}

The Kolmogorov-Smirnov Z test suggested that the data set for all the three constructs were not normally distributed, as the $p$-values were less than 0.05 .

\section{Descriptive statistics}

Since the data for all the three constructs were not normally distributed, median was used as the measure of central tendency and interquartile range (IQR) was employed as the measure of dispersion. 8 out of the 15 indicators of PCB showed a median of 5: strong agreement, 5 indicators showed a median of 4: moderate agreement, 
and the remaining 2 indicators showed a median of 2: less agreement. This finding suggested that majority of the respondents expressed their strong agreement to $\mathrm{PCB}$, providing evidence of a high-PCB among the physicians working in the UE and UW Regions of Ghana. The IQR ranged from 2 to 3, signifying that their responses to PCB were less dispersed. Skewness ranged from 0.07 to 0.49 and kurtosis ranged from 0.32 to 1.16 , confirming that the data on $\mathrm{PCB}$ were significantly different from a normally distributed data, because some of the values were far from zero. This result justified the use of PLS-SEM, which has been deemed suitable even for skewed distributions.

Considering JCM, 12 out of the 19 items showed a median of 3: little agreement, 4 items showed a median of 4: moderate agreement, and 2 items showed a median of 5: strong agreement. This result suggested that respondents were less satisfied their work, as majority of the indicators revealed a median of 3 , implying little agreement to JCM indicators. The IQR of JCM were 1 to 2 , indicating that the responses were not dispersed. Skewness ranged from 0.10 to 0.42 and kurtosis ranged from 0.63 to 1.06 , confirming that the data on JCM were not normally distributed, because some of the values were far from zero. This result vindicated the use of PLS-SEM, which has been deemed suitable even for skewed distributions.

Regarding ETB, 10 out of the 16 the indicators showed a median of 3: occasionally, denoting that ETB was occasionally offered by the physicians, since majority of the indicators revealed a median of 3 . The interquartile range of ETB was 1, signalling that the responses were not wideranging. Skewness ranged from 0.04 to 0.47 and kurtosis ranged from 0.33 to 1.09 , endorsing that the dataset on ETB was not normally distributed, because, some of the values were far from zero. This finding also warranted the use of PLS-SEM, which has been deemed suitable even for skewed distributions.

Table 1. Background Information of Respondents

\begin{tabular}{|c|c|c|c|c|c|}
\hline \multicolumn{4}{|l|}{ Details } & Frequency & Percentage \\
\hline \multirow{2}{*}{\multicolumn{3}{|c|}{ Sex }} & Males & 102 & $47.70 \%$ \\
\hline & & & Female & 112 & $52.30 \%$ \\
\hline \multirow[t]{3}{*}{ Age } & & & $\leq 30$ years & 54 & $25.23 \%$ \\
\hline & & & 31 to 50 years & 132 & $61.68 \%$ \\
\hline & & & $>50$ years & 28 & $13.08 \%$ \\
\hline \multirow{2}{*}{\multicolumn{3}{|c|}{ Employment type }} & Full-time & 158 & $74 \%$ \\
\hline & & & Part-Time & 56 & $26 \%$ \\
\hline \multirow{2}{*}{$\begin{array}{l}\text { Number of } \\
\text { employer }\end{array}$} & worked & with & $<5$ years & 49 & $23 \%$ \\
\hline & & & $>5$ years & 165 & $77 \%$ \\
\hline
\end{tabular}

\section{KMO and Bartlett test of sphericity}

The KMO and Bartlett test of sphericity for the three constructs were computed. Based on the findings, it is confident to say that reliability and validity test was appropriate for this data.

\section{Reliability and validity tests}

Regarding indicator reliability, the indicator loadings for some of the indicators measuring PCB, JCM and ETB were below the minimum threshold of 0.6 . These indicators were PCB01, РCB02, РCB11, РCB12, РCB13, JCM04, JCM08, JCM09, JCM10, JCM12, JCM13, JCM14, JCM15, JCM16, JCM17, JCM18, JCM19, JCM20, ETB-O-1, ETB-O-2, ETB-O-3, ETB-O-7, ETB-O8, ETB-I-1, ETB-I-2, ETBI-3, ETB-I-4, and ETB-I-8. These indicators were therefore deleted from the model. The remaining indictors provided assurance of indicator reliability. Composite reliability values for all the three variables were larger than the cut-off of 0.7 , so higher levels of internal consistency reliability has been demonstrated by all three reflective latent constructs. With respect to convergent validity, all the average variance extracted (AVE) values passed the acceptable AVE of 0.5 , so convergent validity was confirmed. The indicators reliability, composite reliability, and convergent reliability of PCB, JCM and ETB.

Regarding discriminant validity, all the indicators loaded higher with their associated constructs than the remaining constructs. To illustrate, the latent variable PCB's average variance extracted was calculated to be 0.51 , consequently, its square root was 0.71 . This number was greater than the two numbers on the row of PCB, namely 0.67 and -0.69 . The latent variable JCM's average variance extracted was computed to be 0.56 hence its square root was 0.75 . This number was larger than the correlation value in the column of JCM, namely 0.67 and -0.68 . The latent variable ETB's average variance extracted was known to be
0.56 therefore its squared root became 0.75 . This number was also larger than the correlation value of -0.69 in the column of ETB, as well as the correlation value of 0.66 in the row of ETB. Thus, discriminant validity was deemed to have been well established. Simply, the model has been appropriately specified.

\section{Multicollinearity test}

There was also the need to assess the possible multicollinearity among the exogenous latent constructs, so that, according to Hair et al. (2018), it does not bias the regression results. Each set of exogenous latent construct in the model was checked for potential collinearity problem, using multiple regression tools of IBM SPSS Statistics, for Windows, version 24, as Smart PLS software does not provide these numbers. In Wong's (2013) perspective, as a rule of thumb, Variance Inflator Factor (VIF) values above 5.00 are indicative of probable collinearity issues among the predictor constructs. Thus, this study followed this rule of thumb. From the results, there was no multicollinearity among the independent or exogenous latent constructs of PCB and JCM, as the VIF values were lower than 5.00, and the Tolerance level were higher than 0.20 .

\section{$R$-square computation}

Once collinearity was not an issue, the next step was to examine the $R^{2}$ value of the endogenous construct(s). As a guideline, Henseler et al. (2009) advocates that the $R^{2}$ values of $0.70,0.50$, and 0.20 can be considered substantial, moderate, and weak. As depicted in Figure 2, the coefficient of determination $\left(R^{2}\right)$ was 0.97 for the ETB endogenous latent construct, implying that the two exogenous latent constructs (PCB and JCM) substantially explained $96.70 \%$ of the variance in ETB. This percentage was even greater than $70.00 \%$, therefore, the $R^{2}$ of ETB was considered to be 
substantial. This outcome implied that the model fit the data collected and it reflected the overall population. The same model would likely fit if used on another sample drawn from the same population.

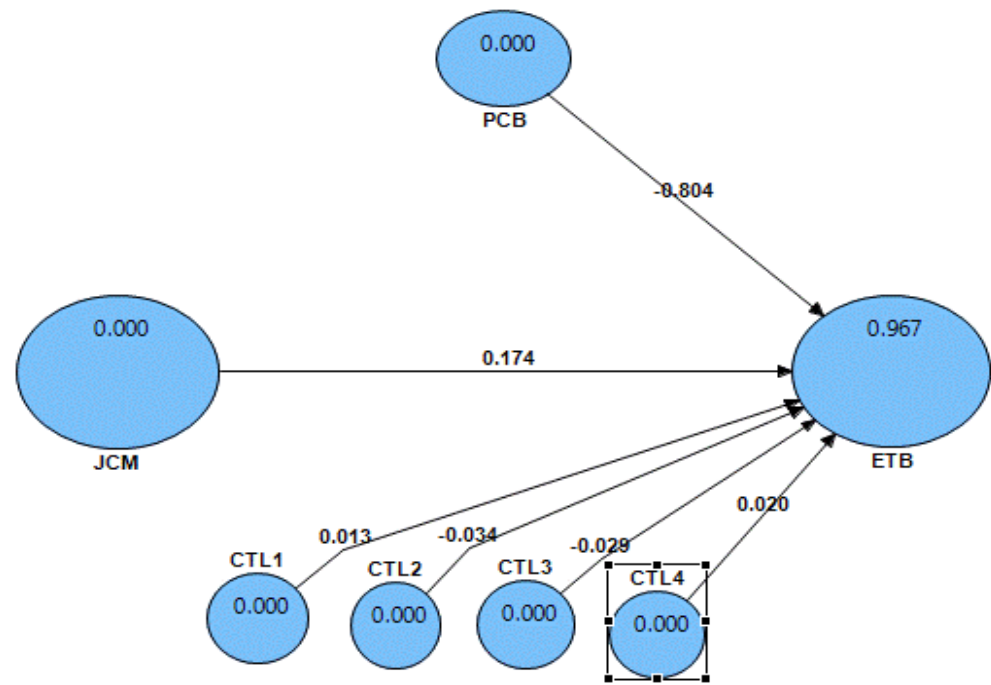

Figure 2. R-square computation

Hypothesis 1: Relationship between job commitment and citizenship behaviour

As hypothesised, the result showed a positive and significant relationship between JCM and ETB among physicians working in the UE and UW Regions of Ghana, after controlling for CTL1, CTL2, CTL3 and CTL4. The path coefficient was 0.94 (Figure 3 ) and t-statistics was 75.39 (Figure 4), which was greater than 1.96 .

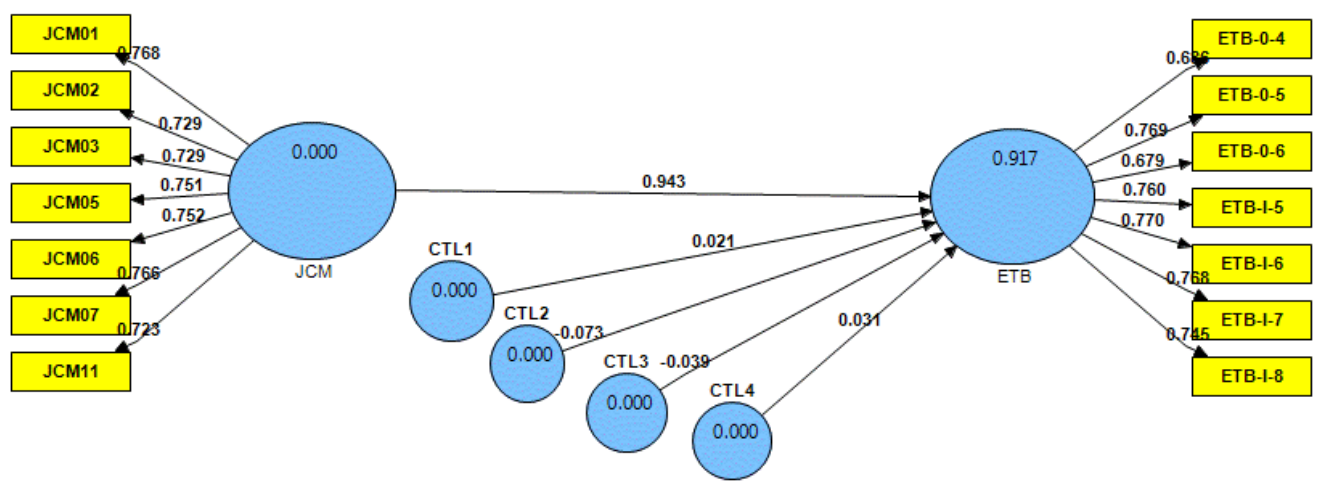

Figure 3. Path coefficient of path linking job commitment to citizenship behaviour

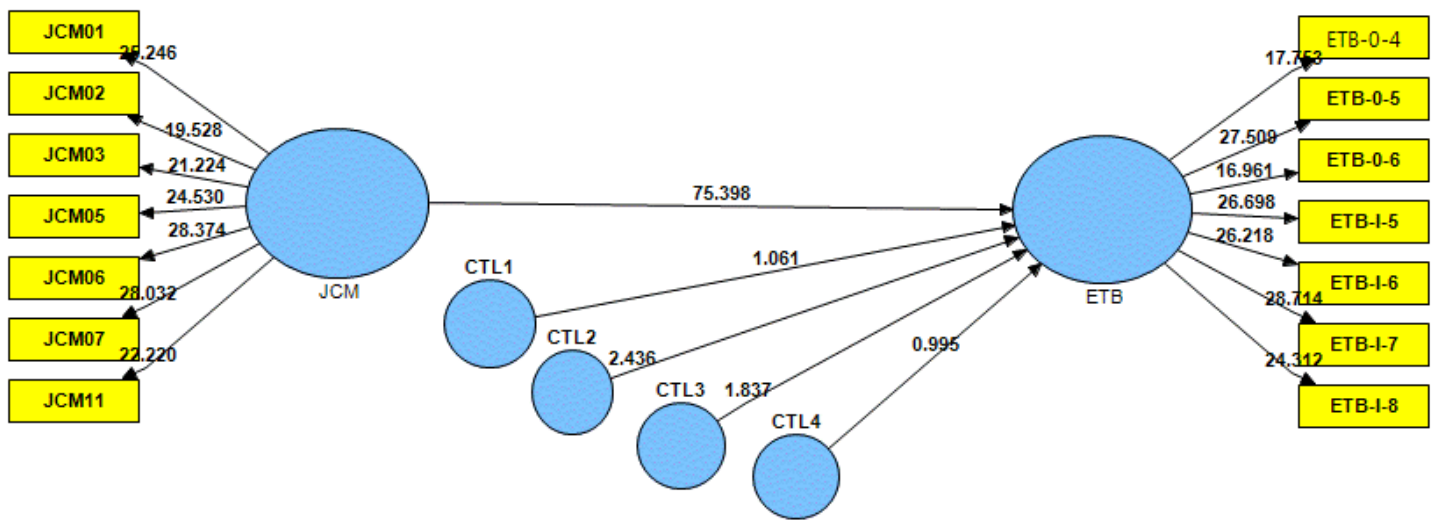

Figure 4. T-statistics of path linking job commitment to citizenship behaviour 
Hypothesis 2: Moderating role of psychological contract breach in job satisfaction-citizenship behaviour relationship

As shown in Figure 5, the interaction term $\mathrm{JCM}^{*} \mathrm{PCB}$ had a negative effect on ETB, as hypothesized. The interpretation of the negative interaction term was that, at the middle of PCB, the relationship between JCM and ETB obtained a value of 0.19 . At a high-PCB, that is, when $P C B$ is increased by one standard deviation point, the relationship between JCM and ETB is decreased by the size of the interaction effect and had the value of $0.19-0.04=0.15$.

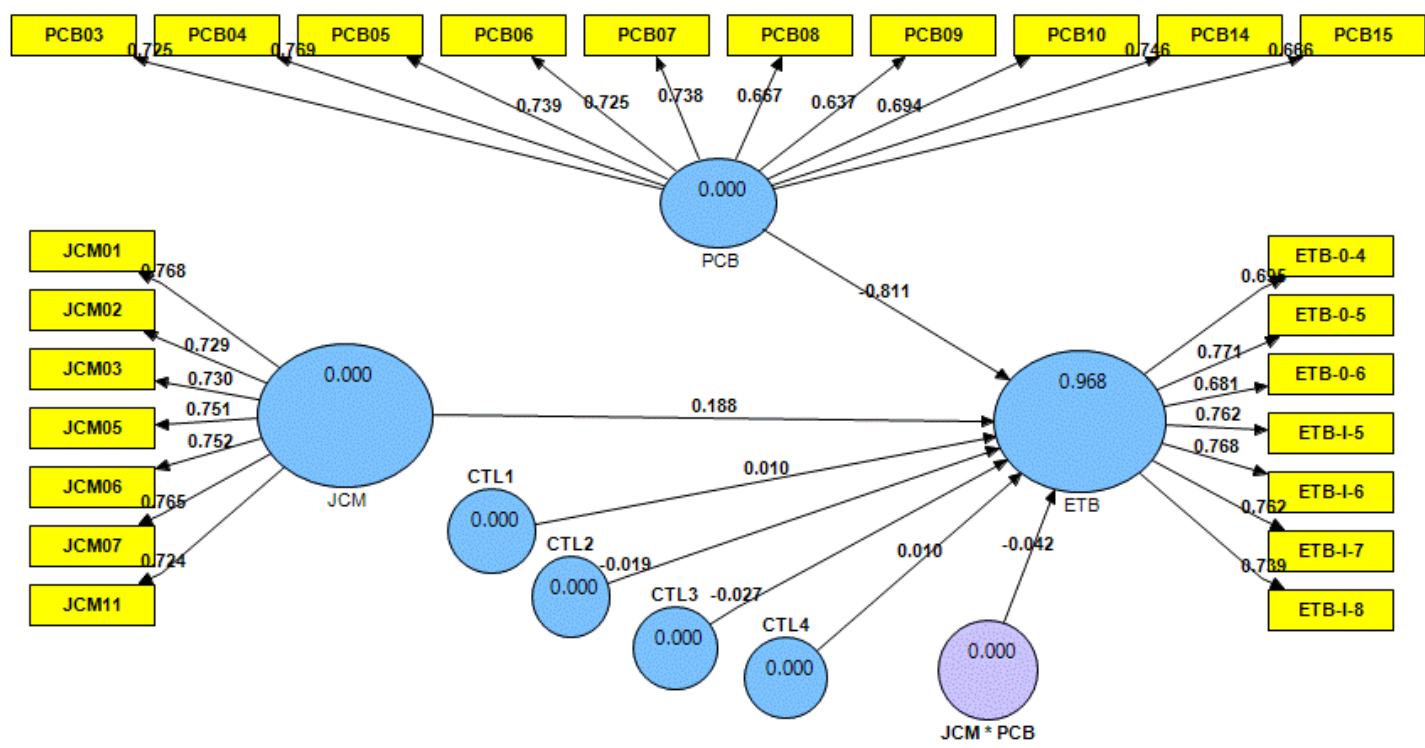

Figure 5. Path coefficient of the moderating role of psychological contract breach in job satisfaction-citizenship behaviour relationship

Therefore, given a high score on PCB, JCT reduced its importance in explaining ETB among physicians working in the UE and UW Regions of Ghana. On the contrary, given a low score on PCB or high psychological contract fulfilment, JCM increased its importance in explaining ETB among physicians working in the UE and UW Regions of Ghana. This finding holds, however, when the interaction term JCT*PCB is revealed to be significant at $5 \%$. From Figure 6 , the tstatistics of the negative interaction term of JCT and PCB (JCM*PCB) was greater than 1.96 (3.88). This finding suggested that $\mathrm{PCB}$ worked as a moderator in the relationship between JCT and ETB.

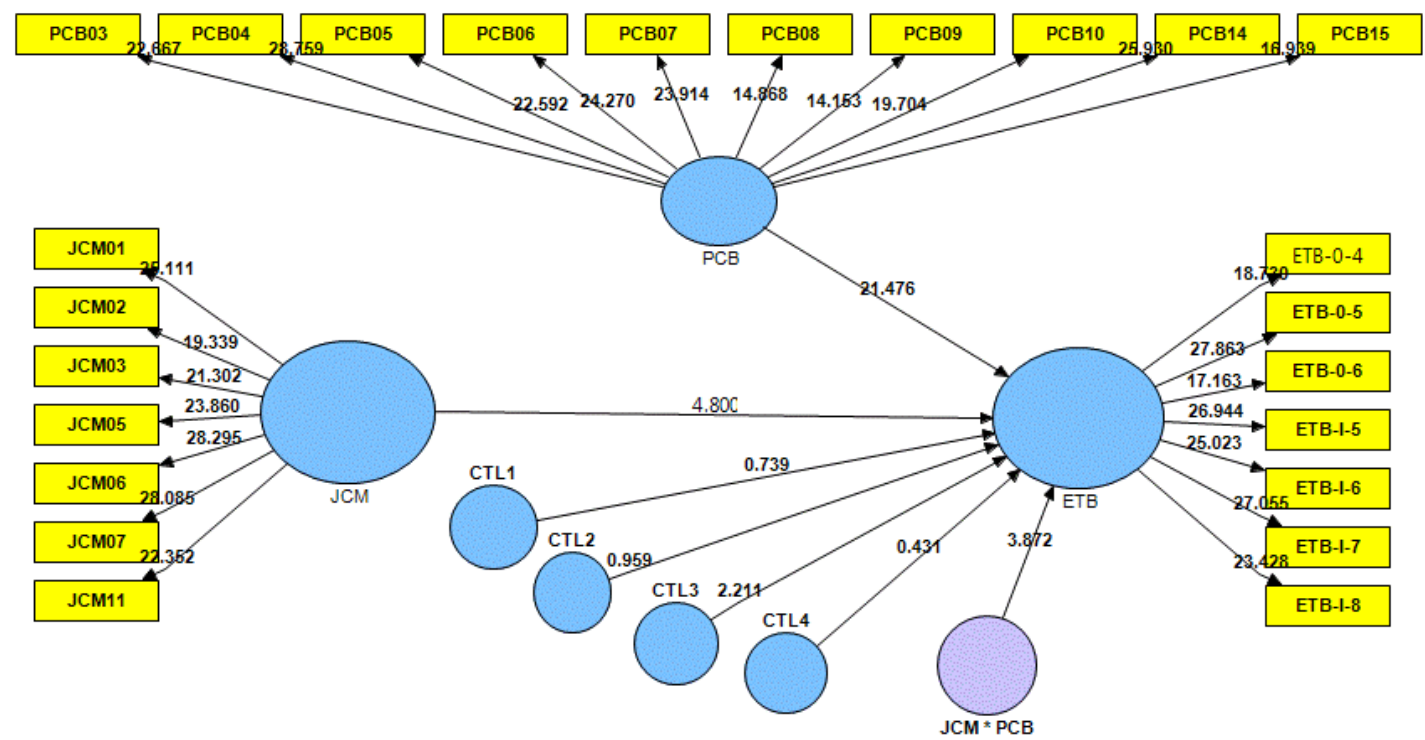

Figure 6. T-statistics of the moderating role of psychological contract breach in job satisfaction-citizenship behaviour relationship 



\section{DISCUSSION}

First and foremost, this study therefore found that the low level of JCM among physicians working in the UE and UW Regions of Ghana led them to show low discretionary behaviours, which may have devastating impacts on coworkers, patients and the health-facility at large. This result extends the ACT, and enhances the results of related existing studies. Secondly, PCB significantly interacted with JCT to predict ETB among physicians working in the UE and UW Regions of Ghana, such that a high-PCB demoralises a committed physician to show ETB. On another hand, a lowPCB or a high psychological contract fulfilment strengthens a committed physician to display ETB, which presents enormous benefits for health-care facilities and their patients. This result, therefore, lengthens the ACT, and improves on the results of existing studies.

\section{RECOMMENDATIONS}

This study recommends that managers of health-care organisations should consider improving the level of JCM among physicians working in stress-pone health zones, such as improving upon their welfare needs, providing study leave, sponsorship for further training, and safe working environment so as to boost ETB among them. This paper also recommends that managers of health-care organisations, particularly Ghana Health Service should improve on their PC with physicians working in stressprone health zones, as it has the tendency to enhance JCM of physicians and increase their tendency to show STB. Besides, managers of health-care organisations must appreciate that, one of their key roles is to manage expectations of physicians, which means clarifying what they believe physicians should achieve, the competencies they should possess, and the values they should uphold, particularly at the time of employment, where promises and commitments are made. Managing these expectations would help reduce future breaches.

Building a balanced, fulfilled and harmonious relationship with physicians will transform the workplace into a more meaningful and purposeful atmosphere. This research thickens the essence of shaping a PC, especially at the recruitment and induction stage when promises and commitments are made by employers on such matters as interesting work, learning and development opportunities, unreasonable demands on employees, feedback on performance, fair treatment, work/life balance, a reasonable degree of security, and a safe working environment. This paper is original, fresh and unique as it offers empirical health-care literature on the moderating effect of PCB, a psychosocial stressor, on the relationship between JCM and ETB by integrating and lengthening three critical theories, namely the SET, RBT and ACT.

\section{Acknowledgement}

The author received no financial support for the research, authorship, and/or publication of this article.

\section{Declaration of Interest Statement}

The author declared no potential conflicts of interest with respect to the research, authorship, and/or publication of this article.

\section{REFERENCES}

Addae, H. M., Parboteeah, P., \& Davis, E. E. (2006). Organisational commitment and intentions to quit: An examination of psychological contract breach in Trinidad and Tobago. International Journal of Organisational Analysis, 14(3), 225-238.

Agbozo, G. K., Ansa-Bonnah, E., Hoedoafia, M. A., \& Atakorah, Y. B. (2018). The role psychological contract plays in organisational behaviour: A case study of a public university in Ghana. European Scientific Journal, 14(23), 34-56.

Akbar, A. B., Udin, S. W., \& Djastuti, I. (2018). Spiritual leadership and employee performance: Mediating role of organisational commitment in Indonesian public university. Journal of Engineering and Applied Sciences, 13(12), 4344-4352.

Anggraeni, A.I., Dwiatmadja, C., \& Yuniawan, A. (2017). The role of psychological contract on employee commitment and organisational citizenship behaviour: A study of Indonesian young entrepreneurs in management action. SA Journal of Industrial Psychology/SA Tydskrif vir Bedryfsielkunde, 43(0), 1-9.

Baer, M., \& Oldham, G. R. (2006). The curvilinear relation between experienced creative time pressure and creativity: moderating effect of openness to experience and support for creativity. Journal of Applied Psychology, 19(4), 963-970.

Blau, P. (1964). Exchange and power in social life. New York: Wiley.

Catholic Agency for Overseas Development (2015). Sustainable development goals: Action for 2030. Retrieved from http://www.statsghana.gov.gh.

Conway, N., \& Briner, R. B. (2005). Understanding psychological contracts at work: a critical evaluation of theory and research. Oxford: Oxford University Press.

Cropanzano, R., Anthony, E.L., Daniels, S.R., \& Hall, A.V. (2017). Social exchange theory: A critical review with theoretical remedies. Academy of Management Annals, 11, 479-516.

Erkutlu, H., \& Chafra, J. (2016). Benevolent leadership and psychological well-being: The moderating effects of psychological safety and psychological contract breach. Leadership \& Organisation Development Journal, 373), 369-386,

Fallon, B. J., \& Rice, S.M. (2015). Investment in staff development within an emergency services organisation: Comparing future intention of volunteers and paid employees. The International Journal of Human Resource Management, 26, 485-500.

Gallup's State of the American Workplace Report (2017). State of the American workplace. https://www.gallup.com/workplace/238085/stateamerican-workplace-report-2017.aspx.

Gardner, D. G. (1986). Activation theory and task design: An empirical test of several new predictions. Journal of Applied Psychology, 173), 411-418.

Gardner, D. G. (1990). Task complexity effects on non-task related movement: A test of activation theory. Organisational Behaviour and Human Decision Process, 45(2), 209-231.

Gardner, D. G., \& Cummings, L. L. (1988). Activation theory and job design: Review and reconceptualisation. In B., Staw, \& L. L. Cummings (Eds), Research in Organisational 
Behaviour, Volume 10 (pp. 81-122). Greenwich, CT: JAI Press.

Ghana Health Service (2017). About us. Retrieved from http://www.ghanahealthservice.org/ghscategory.php?cid=2.

Ghana Health Service (2018). The health sector in Ghana: Facts and figures. http://ghanahealthservice.org/downloads/Facts+Figures 2018.pdf.

Ghana National Healthcare Quality Strategy Report (2017). Key areas to address in leadership and functionality. http://www.moh.gov.gh/wpcontent/uploads/2017/06/National20Quality20Strategy 20Ghana.pdf.

Golden, T. D., \& Veiga, J. F. (2018). Self-estrangement's toll on job performance: The pivotal role of social exchange relationships with co-workers. Journal of Management, 44, 1573-1597.

Guest, D. E., Conway, N., \& Briner, T. (1996). The state of the psychological contract in employment. London: Infrastructure Planning and Design.

Gupta, V. (2019). Impact of perceived organisational support on organisational citizenship behaviour on health care and cure professionals. Management Dynamics, 19(1), $35-44$.

Gupta, V., Agarwal, U. A., \& Khatri, N. (2016). The relationships between perceived organisational support, affective commitment, psychological contract breach, organisational citizenship behaviour and work engagement. Journal of Advanced Nursing, 72(11), 28062817.

Hair, J. F., Risher, J. J., Sarstedt, M., \& Ringle, C. M. (2018). When to use and how to report the results of PLS-SEM. European Business Review.

Hair, J.F., Tomas, H., Ringle, C.M., \& Sarstedt, M. (2014). Premier on partial least squares structural equation modelling.

https://www.researchgate.net/publication/236032728 A_Primer_on_Partial_Least_Squares_Structural_Equatio n_Modeling.

Haque, R., Bhutto, N. A., Sarki, I. H., \& Channa, K. A. (2016). The interaction effect of psychological contract breach on the relationship between psychological capital, work engagement and burnout. Journal of Management and Business, 3(2), 61-77.

Hazrati, S. (2017). Psychological contract breach and affective commitment in Banking sector: The mediation effect of psychological contract violation and trust. Arabian Journal of Business and Management Review, 74), 1-7.

Henseler, J., Ringle, C. M., \& Sinkovics, R. R. (2009). The use of partial least squares path modeling in international marketing. In New challenges to international marketing(pp. 277-319). Bingley: Emerald Group Publishing Limited.

Huy, P. T., \& Takahashi, K. (2018). Determinants of psychological contract breach: An empirical study of Vietnamese employees. Management Research Review, 41, 29-45.

Karagonlar, G., Eisenberger, R., \& Aselage, J. (2016). Reciprocation wary employees discount psychological contract fulfilment. Journal of Organisational Behaviour, 37, 23-40.
Koomson, S., \& Opoku Mensah, A. (2020). Mediating effect of job satisfaction in the relationship between psychological contract breach and organisational citizenship behaviour. Journal of Psychology and Behavioural Science, 8(2), 19-26.

Larbi, M. D. (2015). The implementation of the single spine salary stricture (SSSS) in Ghana. Unpublished master's thesis, University of Ghana, Legon, Ghana. http://ugspace.ug.edu.gh.

Lee, K., \& Allen, N. J. (2002). Organisational citizenship behaviour and workplace deviance: The role of affect and cognitions. Journal of Applied Psychology, 871), 131-142.

Leephaijaroen, S. (2016). Effect of big-five personality trait and organisational commitments on organisational citizenship behaviour of support staff at Ubon Ratchahani Rajabhat University, Thailand. Kasetsart Journal of Social Sciences, 37, 104-111.

Meyer, J. P., \& Allan, N. J. (1997). Commitment in the workplace: Theory research and application. Thousand Oaks, USA: Sage Publications.

Opoku Mensah, A., \& Koomson, S. (2021). Openness to experience moderates psychological contract breachjob satisfaction tie-in. PSU Research Review.

Organ, D.W. (2018). Organisational citizenship behaviour: Recent trends and developments. Annual Review of Organisational Psychology and Organisational Behaviour, 80, 295-306.

Paille, P., \& Mejia-Morelos, J. H. (2014). Antecedents of proenvironmental behaviours at work: The moderating influence of psychological contract breach. Journal of Environmental Psychology, 38, 124-131.

Paillé, P., \& Raineri, N. (2015). Linking perceived corporate environmental policies and employees eco-initiatives: The influence of perceived organisational support and psychological contract breach. Journal of Business Research, 68(11), 2404-2411.

Podsakoff, P. M., Mackenzie, S. B., Lee, J.-Y., \& Podsakoff, N. P. (2003). Common method biases in behavioural research: A critical review of the literature and recommended remedies. Journal of Applied Psychology, 88, 879-903.

Rezaei, J., \& Ortt, R. (2018). Entrepreneurial orientation and firm performance: The mediating role of functional performances. Management Research Review, $8(1), 61-$ 72.

Ringle, C.M., Wende, S., \& Will, A. (2005). SmartPLS 2.0 (M3) Beta. Retrieved from www.smartpls.de.

Robinson, S. L., \& Rousseau, D.M. (1994). Violating the psychological contract: Not the exception but the norm. Journal of Organisational Behaviour, 15, 245-259.

Rousseau, D.M., \& Greller, M.M. (1994). Human resource practices: Administrative contract makers. Human Resource Management, 33, 385-401.

Rousseau, D.M., \& Wade-Benzoni, K.A. (1994). Linking strategy and human resource practices: How employee and customer contracts are created. Human Resource Management, 33, 463-489.

Roy, R., \& Konwar, J. (2019). Can psychological contract create workplace happiness? International Journal of Human Resource Management and Research, 9, 81-88.

Santhanam, N., Kamalanabhan, T. J., Dyaram, L., \& Ziegler, H. (2017). Impact of human resource management practices on employee turnover intentions: Moderating 
role of psychological contract breach. Journal of Indian Business Research, 9(3), 212-228.

Shen, Y., Schaubroeck, J. M., Zhao, L., \& Wu, L. (2019). Work group climate and behavioural responses to psychological contract breach, Frontiers in Psychology, 1067), 1-13. 